\title{
Room temperature dielectric bistability in solution-processed spin crossover polymer thin films
}

Gianluca Bovo, Irene Bräunlich, Walter R. Caseri, Natalie Stingelin, Thomas D. Anthopoulos, Karl G. Sandeman, Donal D. C. Bradley and Paul N. Stavrinou*

Dr. G. Bovo, Prof. T. D. Anthopoulos, Prof. D. D. C. Bradley, Dr. P. N. Stavrinou Department of Physics and Centre for Plastic Electronics The Blackett Laboratory Imperial College London London SW7 2AZ, United Kingdom

E-mail: p.stavrinou@imperial.ac.uk

Dr. I. Bräunlich, Prof. W. R. Caseri

Department of Materials, Wolfgang-Pauli-Strasse 10,

Eidgenössische Technische Hochschule (ETH) Zürich,

Zürich 8093, Switzerland

Prof. N. Stingelin

Department of Materials and Centre for Plastic Electronics, Royal School of Mines, Imperial College London, London SW7 2AZ, United Kingdom

Dr. K. G. Sandeman

Department of Physics

The Blackett Laboratory, Imperial College London, London SW7 2AZ, United Kingdom

Prof. P. N. Stavrinou

Department of Engineering Science, Parks Road, University of Oxford, OX1 3PD, United Kingdom

Prof. D. D. C. Bradley

Departments of Engineering Science and Physics, Mathematical, Physical and Life Sciences Division, University of Oxford, OX1 3PD, United Kingdom

Dr. K. G. Sandeman Department of Physics, Brooklyn College, City University of New York, 2900 Bedford Avenue Brooklyn, NY 11210, USA

Keywords: spin crossover, nanoelectronics, magnetic materials, thin films, bistability 


\begin{abstract}
The spin crossover (SCO) phenomena are a remarkable example of state spin switching at the molecular level. The low- and high-spin states can be reversibly selected through application of external stimulus - often simply a variation in temperature. Since the particular spin-state embodies optical, electronic and structural characteristics, the spin switching can be readily detected or probed using a variety of techniques. In this regard, SCO phenomena show great promise for a range of devices. The key to this uptake is the preparation of high-quality, thin-films capable of retaining SCO properties, and solution-based materials, in particular, provide further opportunities for integration or blending with other functional materials. The present work examines SCO behaviour from two iron(II)-triazole polymers, with short and long side chains, prepared and examined in a variety of formats - from bulk powders to thick and thin films. Magnetic, optical and electronic techniques all verify the SCO behaviour is faithfully maintained for all formats. The two materials serve to highlight the impact on key properties arising from the different density of Fe atoms. The results, all from solution-based materials, are extremely promising and clearly emphasise the growing capability of materials and processing advances associated with SCO materials.
\end{abstract}




\section{Introduction}

Functional materials exhibiting spin crossover (SCO) phenomena provide a remarkable example of spin state switching at the molecular level [see e.g. ${ }^{1,2}$ ]. Electronic low spin (LS) and high spin (HS) configurations may be reversibly selected through external stimuli, which can include variations in temperature, incident light irradiation, magnetic field, solvent effects and even the application of pressure - each of which have proved effective in selecting spin-state. ${ }^{1-3}$ Moreover as the particular state encompasses both electronic and structural characteristics, switching can be readily detected via a number of other material properties, namely optical, magnetic and electrical. It was some 25 years ago that the molecular bistability frequently accompanying SCO transitions was first proposed to be of interest for data storage and display applications. ${ }^{4-6}$ In the years following, interest has developed rapidly, particularly with the emergence of compounds displaying room temperature SCO phenomena. ${ }^{5}$ Present interests include deployment in molecular electronics, nanophotonics and spintronics, appropriating the fast molecular level switching - now no longer confined to low temperatures. ${ }^{7-14}$

Among the vast number of complexes synthesised over the years, the polymeric Fe(II)-triazole compounds have proved versatile SCO systems that combine simple preparation methods with chemical flexibility and stability. ${ }^{15}$ The possibility to functionalize the triazole ligands and/or vary the counter anion, provides further opportunities to tune the SCO temperature and associated hysteresis. ${ }^{16}$ The general formula for this class is $\left[\mathrm{Fe}(\mathrm{R}-\operatorname{trz})_{3}\right] \mathrm{X}_{2} \cdot n \mathrm{H}_{2} \mathrm{O}$ where quasi one-dimensional chains of Fe(II) atoms are bridged by three 4-substituted-1,2,4-triazole ligands (R-trz) and surrounded by monovalent anions $\left(\mathrm{X}^{-}\right)$and uncoordinated water molecules (Figure 1a). ${ }^{17}$ The present work addresses the SCO properties from two such Fe(II)-triazole compounds, which may be prepared and examined in a variety of formats, in 
particular we report on the preparation and assessment of high-quality solutiondeposited thin-films.

Characterisation of SCO compounds often focuses on the magnetic and optical properties. Fe(II) compounds show clear SCO switching between low-spin (LS) diamagnetic $(\mathrm{S}=0)$ and high-spin $(\mathrm{HS})$ paramagnetic $(\mathrm{S}=2)$ states with an attendant thermochromic response, cf. Figure 1b. Fundamental for application in molecular electronic devices are the dielectric and charge transport aspects. ${ }^{18,19}$ In this regard, dielectric bistability, from bulk powders, has been reported for a variety of Fe(II) complexes. ${ }^{20-24}$ Macroscopic samples and nanoparticles of an iron-triazole polymer have been reported to exhibit thermal hysteresis in their transport properties. ${ }^{7,9,14,24-28}$ SCO effects in molecular layers, and even down to single molecules, have been probed electrically. ${ }^{11,29,30}$ Resistivity changes from spin coated films, and nonvolatile memory effects in thermally evaporated SCO complexes have also been reported, albeit with no observed hysteresis. ${ }^{31,32}$

For many technological applications, stable, homogeneous and reproducible thinfilms are desirable. ${ }^{33}$ The vast majority of SCO complexes, often prepared as polycrystalline solids, are not readily processed as thin-films. Their poor solubility and/or easy decomposition at high temperatures often prevent deposition, respectively, from solution and in vacuo. Nevertheless, reports of high-quality uniform thin film fabrication exhibiting SCO properties, from both vacuum evaporation and solution processing, have recently started to emerge. ${ }^{31,34-42}$ The present work continues in this vein and demonstrates the preparation of high-quality spin-coated thin-films of two Fe(II)-triazole compounds. In both cases, SCO phenomena are readily observed, without the need for dilution of the SCO material in a matrix ${ }^{35,38}$ or stabilisation with surfactants. ${ }^{43}$

The two polymeric Fe(II)-triazole SCO compounds (see Figure 1) that we have studied were synthesised as previously described. ${ }^{45-47}$ They differ in terms of the 
substituent groups attached to the apex nitrogen atoms in their triazole ligands. In compound $\mathbf{1}$ this is a small $\mathrm{NH}_{2}$ moiety whereas in compound $\mathbf{2}$ it is a long linear alkyl chain $\left(\mathrm{C}_{18} \mathrm{H}_{37}\right)$. The counter-ions are, similarly, the relatively small 2naphthalene sulfonate and large 4-dodecylbenzenesulfonate, respectively. One obvious consequence of these differences is that there is a higher density of $\mathrm{Fe}(\mathrm{II})$ sites for compound $\mathbf{1}$, whereas compound $\mathbf{2}$ is more soluble, thereby allowing more straightforward preparation of high-quality, homogeneous thin-films. Comparison of these two materials aids in understanding the trade-offs for practical application of SCO compounds. Our study has employed diffuse reflection spectroscopy as a straightforward technique, complementing optical and AFM microscopy, to assess the surface quality of the films. The absorption band characteristic of the low spin state was successfully detected via transmission and reflection spectroscopy in air, demonstrating appreciable oxidative stability. The retention of spin state switching in these circumstances is optically verified by mapping the temperature dependent absorption changes in the UV spectrum. Then, as a first step to deploy these materials inside simple electronic devices, MIM (metal-insulator (SCO)-metal) structures were fabricated and tested by impedance spectroscopy. We extract permittivity values and show that they are in good agreement with values measured in the bulk for similar polymers. More importantly, our results reveal the presence of a thermal hysteresis loop in the dielectric functions for both materials around room temperature. We clearly demonstrate that, in addition to the previous studies on bulk powders, electrical bistability can be achieved for thin-film devices and that impedance spectroscopy acts as a valuable probe to detect SCO properties at the nanoscale.

\section{Experimental Section}


Powders of $\mathbf{1}$ and $\mathbf{2}$ were synthesized following procedures described elsewhere. ${ }^{44,45}$ Solutions of 1 with molar concentration in the range $0.02-0.07 \mathrm{M}$ were prepared by dissolving the corresponding powder in N,N-dimethylformamide (anhydrous, 99.8\%, Sigma Aldrich) in nitrogen atmosphere. Solutions of $\mathbf{2}$ with molar concentration in the range $0.01-0.03 \mathrm{M}$ were prepared by dissolving the corresponding powder in toluene (anhydrous, 99.8\%, Sigma Aldrich) in nitrogen atmosphere. Both solutions of $\mathbf{1}$ and $\mathbf{2}$ were stirred and heated at $100{ }^{\circ} \mathrm{C}$ to achieve complete dissolution before filtering (PTFE filters, $0.45 \mu \mathrm{m}$ pores). Micrometer-thick films were prepared by dropcasting on quartz substrates. Thin films of 1 (thickness in the range $20-100 \mathrm{~nm}$ ) were deposited from hot solutions $\left(100^{\circ} \mathrm{C}\right)$ via spin coating $(1000-5000 \mathrm{rpm}$ rotation speed). Thin films of 2 (thickness in the range $100-1000 \mathrm{~nm}$ ) were deposited from either hot $\left(100^{\circ} \mathrm{C}\right)$, room temperature or gelled solutions via spin coating (1000 $5000 \mathrm{rpm}$ rotation speed). All processing steps were carried out in an inert atmosphere inside a glovebox. The film thicknesses were measured with a Veeco Dektak 150 profilometer. Atomic force microscopy was carried out using an Agilent 5500 in close-contact (tapping) mode.

\subsection{Magnetic susceptibility measurements}

Variable-temperature dc-magnetization measurements were performed on powders and films using a Quantum Design 9 Tesla PPMS-Vibrating Sample Magnetometer (VSM). A 1 T magnetic field and a heating/cooling rate of $1 \mathrm{~K} / \mathrm{min}$ in the range 200 $380 \mathrm{~K}$ were applied inside a chamber purged with helium at a pressure of $\sim 25$ Torr. Experimental data were corrected for the diamagnetism of the sample (estimated from Pascal's constants) and for the magnetic contribution of the sample holder.

\subsection{Optical characterisation}


Diffuse reflectance, transmission and specular reflection UV-Vis-NIR spectra of the thin films were collected over the wavelength range 220 - $1400 \mathrm{~nm}$ using a Shimadzu UV-2600 spectrophotometer equipped with an ISR-2600Plus integrating sphere. Temperature dependent transmission spectra of films were acquired in air over the temperature range 298-383 K with a Perkin Elmer Lambda25 Spectrometer and a water-cooled Specac Electrical Heating Jacket. The sample was held for 3 min at each temperature step before starting the data acquisition. Optical microscopy images were obtained in reflection mode using an Olympus BX51 microscope.

\subsection{Electrical M-I-M devices and characterisation}

Al metal stripe electrodes (40 $\mathrm{nm}$ thickness) were deposited through shadow masks onto glass substrates by thermal evaporation $(1 \AA / s)$ in high vacuum. Thin films of $\mathbf{1}$ or 2 were spin-coated on top and, finally, top Al stripe electrodes were evaporated with their long axis perpendicular to that of the bottom contacts to obtain Al/polymer/Al (M-I-M) structures. To characterise the low frequency dielectric properties from the MIM structures impedance spectroscopy measurements were performed using a Schlumberger SI 1260 impedance/gain phase analyser over the 10 $10^{6} \mathrm{~Hz}$ range. Once the complex impedance, $\hat{\mathrm{Z}}(\omega)$ is recorded this may be easily converted to the complex capacitance $\hat{C}(\omega)$ of the device

$$
\hat{C}(\omega)=\frac{1}{i \omega \hat{Z}(\omega)}
$$

Following this and knowing the geometrical parameters of the structures, i.e. the active area (A) and the SCO film thickness (d), it is possible to extract the complex dielectric permittivity $\hat{\varepsilon}(\omega)$

$$
\hat{\varepsilon}(\omega)=\frac{d}{\varepsilon_{0} A} \hat{C}(\omega)
$$


where $\varepsilon_{0}$ is the vacuum permittivity. ${ }^{46}$ Frequency sweeps were carried out isothermally at temperatures between $240 \mathrm{~K}$ and $380 \mathrm{~K}$ inside a vacuum probe station (pressure $\sim 10^{-5}$ mbar).

\section{Results and Discussion}

\subsection{SCO compounds and magnetic susceptibility}

The first compound, $\left[\mathrm{Fe}\left(\mathrm{NH}_{2} \mathrm{trz}\right)_{3}\right]\left(2 \mathrm{~ns}_{2}\right)_{2}\left(\mathrm{NH}_{2}\right.$ trz: 4-amino-1,2,4-triazole, 2ns-: 2naphthalene sulfonate) (1) belongs to the amino-triazole Fe(II) polymer class, known to feature hysteretic spin transitions above $200 \mathrm{~K}$, although generally offering very low solubility in organic solvents. ${ }^{16,17,47}$ The high degree of cooperativity, i.e. the response of the structure of the compound in tandem with the SCO transition, frequently observed stems from strong short-range elastic interactions between Fe centres via rigid amino-triazole bridges and the extended network of long-range interchain bonds. ${ }^{47,48}$ Recent work, however, showed $\mathbf{1}$ to be soluble in dimethylformamide (DMF), enabling the preparation of thick $(\sim 100 \mu \mathrm{m})$ films exhibiting solid state SCO close to room temperature. ${ }^{44,49}$ The second coordination polymer is a relatively new alkyl-substituted Fe(II)-triazole complex, $\left[\mathrm{Fe}\left(\mathrm{C}_{18} \mathrm{trz}\right)_{3}\right](\mathrm{DBS})_{2}\left(\mathrm{C}_{18}\right.$ trz: 4-octadecyl-1,2,4-triazole, $\mathrm{DBS}^{-}: 4$ dodecylbenzenesulfonate) (2), whose SCO behaviour was recently confirmed from bulk optical and DSC measurements. ${ }^{45}$ In contrast to compound 1, alkyl-triazole derivatives can form stable solutions that gel at low concentrations and also exhibit liquid crystalline properties. Earlier reports also noted that increasing the size of the n-alkyl substituent on the triazole ligand of chain-like spin-transition compounds has a tendency to lower the cooperativity. ${ }^{16,50-54}$ 
To set the baseline for the following thin-film studies, temperature-dependent measurements of the magnetic susceptibility $(\chi)$, for fine microcrystalline powders, are shown in Figure 1c in the form of $\chi \mathrm{T}$ vs $\mathrm{T}$ plots. Both materials display clear room temperature $\mathrm{SCO}$ with evident hysteresis. Transition temperatures, at $\mathrm{T}_{\text {up }}=331$ $\mathrm{K}$ on heating and $\mathrm{T}_{\text {down }}=306 \mathrm{~K}$ on cooling are found for $\mathbf{1}$, comparable with those reported in reference 45 , while those for $2, \mathrm{~T}_{\text {up }}=318 \mathrm{~K}$ and $\mathrm{T}_{\text {down }}=306 \mathrm{~K}$, are consistent with results presented in reference 47 . This is, however, the first time that full magnetisation curves are reported for these compounds. Hysteresis widths of $\Delta \mathrm{T}=25 \mathrm{~K}$ and $\Delta \mathrm{T}=$ $12 \mathrm{~K}$ are recorded for $\mathbf{1}$ and $\mathbf{2}$ respectively. The smaller width and less-abrupt $\mathrm{LS} \Leftrightarrow \mathrm{HS}$ transitions suggest a relatively lower degree of cooperativity for the alkyltriazole compound $\mathbf{2}$, in line with the observations reported in reference 45 . We also note that these $\chi \mathrm{T}$ curves are found to be reproducible, retaining the spin transition shapes and hysteresis widths over many successive cycles. Consideration of the raw magnetization data (Figure S1) highlights the weaker ( 2.2 times) intensity for compound $\mathbf{2}$ compared to $\mathbf{1}$, consistent with the lower density of Fe(II) centers in the alkyl-substituted polymer: the ratio of molar mass between $\mathbf{1}$ and $\mathbf{2}$ is $\sim 2.3$. When expressed in terms of $\chi \mathrm{T}$, the values for the paramagnetic HS state, $\left(3.40 \mathrm{~cm}^{3} \mathrm{~K} \mathrm{~mol}^{-1}\right.$ and $3.57 \mathrm{~cm}^{3} \mathrm{~K} \mathrm{~mol}^{-1}$ at $380 \mathrm{~K}$ respectively for $\mathbf{1}$ and 2) are in good agreement with those expected for Fe(II) SCO compounds (see e.g. reference 15). Considering the diamagnetic LS state at $200 \mathrm{~K}$, we find a residual HS paramagnetism for both compounds, estimated at $10 \%$ for $\mathbf{1}$ and $20 \%$ in compound $\mathbf{2}$. Such residual effects are often attributed to the influence of chain end (terminal) Fe(II) atoms, which remain HS for the whole temperature range due to coordination by water molecules or monodentate triazole ligands. ${ }^{55}$ The greater residual HS fraction observed in $\mathbf{2}$ may be 
rationalised by a larger number of terminal $\mathrm{Fe}(\mathrm{II})$ atoms, suggesting the average chain length in the alkyl-polymer is smaller in comparison to $\mathbf{1 .}{ }^{\mathbf{5 4}, \mathbf{5 5}}$ Shorter chain lengths are also expected to reduce the degree of cooperativity and in this regard, the lessabrupt transitions and narrower hysteresis observed in Figure 1c for $\mathbf{2}$ support this expectation. $^{16,54}$

\subsection{Assessment of SCO thin-films from solution}

Powders of compound $\mathbf{1}$ were dissolved in DMF following vigorous and protracted stirring. To enhance the solubility of the SCO compound we found raising the solution temperature while stirring proved effective, in line with most common polymers. ${ }^{56}$ The solutions, purple at room temperature (LS) and colourless when heated above $50{ }^{\circ} \mathrm{C}$ (HS), were prepared in inert atmosphere to avoid oxidation of $\mathrm{Fe}(\mathrm{II})$ to $\mathrm{Fe}(\mathrm{III})$. Above $50{ }^{\circ} \mathrm{C}$ the solubility drastically improved and no material was left undissolved. Nanometric thickness films were prepared by spin-coating solutions onto fused silica substrates, with the thickness $(20-100 \mathrm{~nm})$ varied by tuning the rotation speed and solution concentration. The solution temperature had a profound impact on the quality of the resulting thin-films. Films obtained from solutions at room temperature $\left(20^{\circ} \mathrm{C}\right)$, though transparent, appeared slightly cloudy to the eye, in contrast to those cast when the solution was still hot, typically above $60{ }^{\circ} \mathrm{C}$, that were fully clear. Images from AFM and optical microscopy, shown in Figure 2a (additional data in Figure S2), serve to further highlight the difference; strongly indicating that inhomogeneous layers are obtained when $20^{\circ} \mathrm{C}$ solutions are employed. Diffuse reflection (DR) spectroscopy offered further evidence, and a comparison for three thin film samples prepared from solutions with the same SCO polymer concentration but different temperatures $\left(20^{\circ} \mathrm{C}, 60^{\circ} \mathrm{C}\right.$ and $\left.100{ }^{\circ} \mathrm{C}\right)$ are also shown in Figure 2a. Across the visible spectrum, significantly more scattering occurs 
for the sample prepared from a $20^{\circ} \mathrm{C}$ solution, compared to those prepared from hot solutions; where the highest temperature solution $\left(100^{\circ} \mathrm{C}\right)$ yields marginally better results. The accompanying microscopy images are consistent with the former being rather inhomogeneous while the latter, hot solution films, are more homogeneous. The measured AFM rms roughness for the $100{ }^{\circ} \mathrm{C}$ solution films was $1.8 \mathrm{~nm}$, while the films prepared from $20{ }^{\circ} \mathrm{C}$ solutions were discontinuous and had a local rms roughness of $34 \mathrm{~nm}$. One explanation for these findings is that the elevated temperature, i.e. at least $60{ }^{\circ} \mathrm{C}$ in Figure 2a, ensures that even the smallest crystallites of the SCO compound are dissolved. If left undissolved, these crystallites may act as nuclei for further crystallization, which may take place preferentially during the slow evaporation of DMF at room temperature. ${ }^{57,58}$ Thus casting from higher solution temperatures most likely serves a twofold purpose: it promotes more rapid solvent evaporation and limits the number of pre-formed nucleation centres. Further findings appear in the supplementary information, particularly DR values measured from a range of hot cast samples that also highlight an increase of scattering with increasing film thickness (Figure S3). All further results presented hereafter for compound $\mathbf{1}$ are from hot cast films at $100^{\circ} \mathrm{C}$.

The alkyl-substituted compound $\mathbf{2}$, on the other hand, is known to be soluble in most aprotic solvents such as toluene. ${ }^{45}$ Homogeneous films, with thicknesses up to several hundred nanometers, can be readily obtained. In contrast to compound $\mathbf{1}$, spin coating films from either hot or room temperature solutions did not influence the quality of the films, cf. Figure S4 in supplementary information. However, if allowed to rest for several hours, solutions of compound $\mathbf{2}$ tend to form gels with a much higher viscosity. Spin-coating from the gels, the films obtained exhibited very low DR scattering across the visible spectrum. Furthermore the DR values were found to be independent of thickness, confirming that high-quality layers up to $1 \mu \mathrm{m}$-thickness can be thus 
deposited; evident from the clear Fabry-Perot oscillations for thick $(750 \mathrm{~nm})$ films, seen in both transmission and (specular) reflection spectra as shown in Figure 2b.

Having demonstrated the ability to produce high-quality thin films from each compound, we now turn to assessment of their stability, and importantly, their ability to retain reversible SCO properties. Optical measurements provide a straightforward means to read and verify the spin-state through SCO-related changes in the absorption spectrum. ${ }^{59}$ A recognised number of SCO-related optical transitions that, with associated molecular orbitals located on or in close proximity to the metal ion, reflect changes in the specific spin-state are accessible across the UV-Visible-NIR spectrum. ${ }^{60}$ Transitions underpinning the perceptible colour change for powder (see Figure 1b) or thick film samples of $\mathbf{1}$ and $\mathbf{2}$ appear in the visible spectrum, at around $535 \mathrm{~nm}$ (cf. Figure S5). In producing thick films by drop-casting, hot solutions are initially colourless (polymer in HS state) but visibly change to purple (polymer LS state) during cooling and evaporation of the solvent. Thin (sub-micron) films, conversely appear transparent and colourless, regardless of the spin-state, owing to the low oscillator strength of the $535 \mathrm{~nm}$ band (molar extinction coefficient typically $<100 \mathrm{~L} \mathrm{~mol}^{-1} \mathrm{~cm}^{-1}$ in solution). ${ }^{61}$ Optically probing the signature of the spin state at $535 \mathrm{~nm}$ in such thin-films is therefore challenging, and more recent attention has been directed to the stronger transitions occurring in the UV region or to indirectly probing the spin-state via fluorescence energy transfer. ${ }^{62}$ From an optical perspective, highquality thin-film formats introduce other considerations that are expected to complicate the clear identification of the spin-state. Specular reflection from highquality interfaces can easily mask a (relatively) small absorption feature; for very thin films $(<100 \mathrm{~nm})$, the reflection $(\mathrm{R})$ can exceed 10\% (Figure S6a). However, once reflection spectra have been acquired, they may be combined with transmission measurements (T) to reveal the LS transition. Figure S6 (in supplementary 
information) highlights this procedure for a range of thin-film samples of compound $\mathbf{1}$. Increasing the film thickness to increase the OD of the spin state transition, brings into play optical interference effects. For sufficient thicknesses, typically $>180 \mathrm{~nm}$, the single layer of SCO material will exhibit clear Fabry-Perot oscillations, particularly in spectral regions where the absorption is low. These are clearly evident in Figure 2b, for both transmission and specular reflection measurements. While these oscillations usefully evidence the high-quality interfaces from the homogeneous thinfilm, observation of the $535 \mathrm{~nm}$ spin transition is nearly impossible without due consideration of both reflection and transmission spectra to cancel the interference effects. Figure 2c reveals the clear LS transition for a $750 \mathrm{~nm}$ thickness film of 2 following correction of the raw spectral data. With the LS transition now clearly observed at $535 \mathrm{~nm}$, in thin-films from both compounds, their respective absorption coefficients may be determined and are found to be $220 \pm 15 \mathrm{~cm}^{-1}$ for compound 1 and $68 \pm 5 \mathrm{~cm}^{-1}$ for compound 2 ; both in good agreement with the values extracted from thick dropcast films (Figure S4). It is interesting to note that the absorption coefficient of $\mathbf{1}$ is $\sim 3.2$ times larger than that found for $\mathbf{2}$, suggesting that, chemical differences aside, the density of iron atoms between the two compounds also underpins the strength of the optical transitions. By directly observing the transition associated with the LS state for samples measured in air it is evident that the resulting thin films of $\mathbf{1}$ and $\mathbf{2}$ are indeed stable, otherwise Fe(II) oxidation to Fe(III) would have removed evidence of the LS absorption band. ${ }^{44}$ Further evidence of film stability, and importantly the retention of the SCO switching behaviour can be obtained by mapping the strong charge transfer (CT) transitions in the UV region of the spectrum. ${ }^{62-64}$ For both compounds, absorption from the CT transitions at $280 \mathrm{~nm}$ drastically reduces as the samples switch from LS to HS upon heating (Figure 3). The LS to HS transitions occur at $\mathrm{T} \sim 338 \mathrm{~K}$ and $325 \mathrm{~K}$ for $\mathbf{1}$ and $\mathbf{2}$ respectively, slightly higher than found for the powders shown in Figure 1, but compatible with the 
temperatures measured for hydrated powder samples. ${ }^{45,47,49}$ In both cases, once the films were allowed to cool back to the LS state the CT absorption was fully recovered, confirming the reversibility of the SCO switching in air.

\subsection{Electrically assessing the spin-state}

Having demonstrated the basic SCO switching properties of our compounds we next sought to explore their potential for device application, specifically in a metalinsulator-metal (MIM) diode configuration. Previous electrical device studies have focused on samples in which the SCO compounds were blended with conducting polymers. ${ }^{12}$ Here we use neat (insulating) films and focus on the dielectric response. The MIM structures were fabricated by spin-coating thin films of $\mathbf{1}$ and $\mathbf{2}$ onto aluminium stripe electrodes vacuum-deposited on glass substrates. Al top electrodes were evaporated directly onto the SCO polymer, aligned with their long axis perpendicular to that of the bottom electrodes (see Figure 4a). MIM structures were fabricated with different active areas (defined by the overlaps between top- and bottom-electrodes) and their complex impedances $\hat{Z}(\omega)$ were measured. The extracted capacitance values and SCO thicknesses were used to confirm the expected scaling of capacitance with device area (see Figure $\mathbf{4 b}$ and Figure $\mathbf{S 7}$ in supplementary information). These initial checks provided further reassurance of the homogeneous nature and integrity of our thin-film SCO devices. Linear fitting of the data allow us to report, for the first time, estimates for the real part of the permittivity $\left(\varepsilon^{\prime}\right)$ for each compound. Extracted values of $3.85 \pm 0.03$ and $3.11 \pm 0.03$ were obtained for $\mathbf{1}$ and $\mathbf{2}$ respectively. Our value from spin-coated films of $\mathbf{1}$, compare favourably with those found from a similar (but not identical) amino-triazole SCO compound, with a compact counteranion, extracted from pressed powders ${ }^{20}$. The comparatively lower permittivity values found for thin-films of $\mathbf{2}$ may again be understood as a 
consequence of the reduced $\mathrm{Fe}(\mathrm{II})$ density resulting from the large counterions and $\mathrm{R}$ groups used in this compound; complementing our earlier observations (above) of a reduced magnetic susceptibility and optical absorption relative to compound $\mathbf{1}$. The imaginary part of the permittivity, $\varepsilon^{\prime \prime}$, accounts for dielectric losses in the medium and represents the resistive part of the dielectric response (see supplementary information for further details, Figure S7). When converted to represent an electrical conductivity, we find values $<10^{-9} \mathrm{~S} \mathrm{~cm}^{-1}$ for both compounds, confirming the insulating nature of this general class of materials, in line with previous reports. ${ }^{9}, 14,25,28,32$

The temperature dependence of the dielectric response upon SCO was examined by performing isothermal frequency sweeps at a range of temperatures spanning the transition and for both heating and cooling cycles. However, extracting the dielectric permittivity becomes difficult as the temperature is varied; SCO compounds are known to undergo a remarkable change in volume as the spin transition occurs, via distortion of the coordination sphere of the metal centre (see e.g. reference 1). In powder form, unit cell volume changes of up to $10 \%$ have been observed ${ }^{65}$ and a concomitant thickness change is expected for thin-film samples. Therefore, in the absence of accurate measurements of the film thickness at each temperature step, no $a$ priori assumptions can be made about neglecting this contribution. To circumvent the issue, we consider, instead, the ratio $\varepsilon^{\prime \prime} / \varepsilon^{\prime}$ of the imaginary and real parts of the permittivity, also known as the loss tangent, $\tan (\delta)$. This ratio $\left(\varepsilon^{\prime \prime} / \varepsilon^{\prime}\right)$, like the equivalent capacitance ratio $\left(\mathrm{C}^{\prime \prime} / \mathrm{C}^{\prime}\right)$, is independent of both geometry and film thickness.

The temperature dependence of $\tan (\delta)$ is shown in Figure $4 \mathbf{c}$ for a device comprising a $30 \mathrm{~nm}$ thickness film of compound $\mathbf{1}$ and in Figure $\mathbf{4 d}$ for a $400 \mathrm{~nm}$ thickness film of compound 2. Clear hysteresis loops are observed around room temperature. To further aid comparison, magnetization curves from the powders presented in Figure 
$1 \mathrm{c}$ are superimposed to reveal that the thin-film SCO dielectric response occurs over similar temperature ranges. For $\mathbf{1}$, the LS-HS transitions are quite abrupt, taking place around $330 \mathrm{~K}$ on heating and $300-305 \mathrm{~K}$ on cooling, describing a $25-30 \mathrm{~K}$ wide loop. These values are largely unaffected by the specific frequency considered, although data acquired below $1 \mathrm{kHz}$ become increasingly noisy. Within the hysteresis temperature region, the change in $\tan (\delta)$ between cooling and heating is as much as $\Delta \tan (\delta)=50 \%$, depending on frequency (see Figure S8). Loss tangent curves for 2 present a less abrupt SCO transition, again mirroring the magnetisation curves from powders and suggesting a lower cooperativity. While the hysteresis region appeared over a consistent temperature range for all frequencies, the detailed shape of the heating/cooling curves were found to vary remarkably according to the specific choice of frequency (see Figure S9). In general, the SCO transition was complete at $330 \mathrm{~K}$ upon heating and at $270 \mathrm{~K}$ on cooling, with $\Delta \tan (\delta)$ values of up to $35 \%$ within the hysteresis loop. Multiple thermal cycling of samples confirms retention of the dielectric switching.

To the best of our knowledge, this is the first demonstration of thermal hysteresis in the SCO dielectric properties of solution-processed thin-films. It is all the more encouraging given that the MIM device configuration used for the dielectric characterization is far from ideal, with large mm-wide contacts and no buffer layer to prevent metal diffusion into the film during temperature cycling. We were nonetheless able to show that the SCO observed in bulk powders, is maintained for spin-coated nanometric thickness layers; the highlight being the close correspondence in the $\tan (\delta)$ monitored SCO transition for compound $\mathbf{1}$ and powder sample magnetic susceptibility data (Figure 4c). Given that previous studies have generally found SCO films to present more gradual transitions than powders, ${ }^{39,40,66}$ this was an unexpected, 
but welcome outcome and particularly encouraging since abrupt switching is desirable in terms of technological application.

\section{Conclusions}

In summary, we have demonstrated the clear retention of SCO properties from solution processed thin films of Fe(II)-triazole based polymers. Two compounds have been examined, both exhibiting room-temperature SCO phenomena while differing in the density of $\mathrm{Fe}(\mathrm{II})$ atoms. Assessing the compounds, along with the resulting highquality homogeneous thin films, a range of experimental techniques have been used. In several instances, the impact on key properties arising from the different density of Fe atoms has been noted. A comprehensive measurement of the optical response, which included transmission and (diffuse and specular) reflection, allowed direct observation of the thermochromic LS state absorption in the thin-film format, thereby confirming the stability in the thin-film format and, consequently, the retention of SCO properties. As a final verification to the production of smooth, stable and pinhole-free nanometric thin films, electrically addressed MIM structures were fabricated. The insulating thin-films, from both compounds, displayed room temperature dielectric bistability that faithfully mirrored the SCO bistability observed from the powder compounds. The tantalising wealth of SCO properties has long hinted at some exciting new technologies. For applications, the thin film format is crucial and solution-based materials, in particular, provide further opportunities through integration or blending with other functional materials. The present work, demonstrating thin-film SCO properties from solution-based materials is extremely promising and clearly highlights the growing capability of materials and processing advances associated with SCO materials. 
Acknowledgements: We cordially thank Paul Smith for his encouragement and continuing support of this work. GB and PS would like to acknowledge the Leverhulme Trust for financial support. IB and WRC are grateful for financial support from the Swiss National Science Foundation and the COST Action cm1302 Smart Inorganic Polymers.

1. P. Gütlich and H. Goodwin, in Spin Crossover in Transition Metal Compounds I, eds. P. Gütlich and H. A. Goodwin, Springer Berlin Heidelberg, 2004, vol. 233, ch. 1, pp. 1-47.

2. A. Bousseksou, G. Molnar, L. Salmon and W. Nicolazzi, Chem Soc Rev, 2011, 40, 3313-3335.

3. D. Gentili, N. Demitri, B. Schafer, F. Liscio, I. Bergenti, G. Ruani, M. Ruben and M. Cavallini, Journal of Materials Chemistry C, 2015, 3, 7836-7844.

4. O. Kahn, J. Kröber and C. Jay, Advanced Materials, 1992, 4, 718-728.

5. O. Kahn, Science, 1998, 279, 44-48.

6. P. Gütlich and A. Hauser, Coordination Chemistry Reviews, 1990, 97, 1-22.

7. A. Rotaru, J. Dugay, R. P. Tan, I. A. Guralskiy, L. Salmon, P. Demont, J. Carrey, G. Molnár, M. Respaud and A. Bousseksou, Advanced Materials, 2013, 25, 1745-1749.

8. G. Felix, K. Abdul-Kader, T. Mahfoud, I. A. Gural'skiy, W. Nicolazzi, L. Salmon, G. Molnar and A. Bousseksou, J Am Chem Soc, 2011, 133, 1534215345 .

9. F. Prins, M. Monrabal-Capilla, E. A. Osorio, E. Coronado and H. S. van der Zant, Adv Mater, 2011, 23, 1545-1549.

10. H. J. Shepherd, I. y. A. Gural'skiy, C. M. Quintero, S. Tricard, L. Salmon, G. Molnár and A. Bousseksou, Nat Commun, 2013, 4.

11. T. Miyamachi, M. Gruber, V. Davesne, M. Bowen, S. Boukari, L. Joly, F. Scheurer, G. Rogez, T. K. Yamada, P. Ohresser, E. Beaurepaire and W. Wulfhekel, Nat Commun, 2012, 3, 938.

12. T. Liu, H. Zheng, S. Kang, Y. Shiota, S. Hayami, M. Mito, O. Sato, K. Yoshizawa, S. Kanegawa and C. Duan, Nat Commun, 2013, 4.

13. S.-i. Ohkoshi, K. Imoto, Y. Tsunobuchi, S. Takano and H. Tokoro, Nat Chem, 2011, 3, 564-569.

14. Y.-S. Koo and J. R. Galán-Mascarós, Advanced Materials, 2014, 26, 67856789.

15. M. Carmen Muñoz and J. Antonio Real, in Spin-Crossover Materials, John Wiley \& Sons Ltd, 2013, DOI: 10.1002/9781118519301.ch4, pp. 121-146.

16. O. Roubeau, Chemistry - A European Journal, 2012, 18, 15230-15244.

17. A. Grosjean, N. Daro, B. Kauffmann, A. Kaiba, J. F. Letard and P. Guionneau, Chem Commun (Camb), 2011, 47, 12382-12384.

18. E. Ruiz, Physical Chemistry Chemical Physics, 2014, 16, 14-22.

19. P. N. Martinho, C. Rajnak and M. Ruben, in Spin-Crossover Materials, John Wiley \& Sons Ltd, 2013, DOI: 10.1002/9781118519301.ch14, pp. 375-404. 
20. A. Bousseksou, G. Molnar, P. Demont and J. Menegotto, Journal of Materials Chemistry, 2003, 13, 2069-2071.

21. T. Guillon, S. Bonhommeau, J. S. Costa, A. Zwick, J.-F. Létard, P. Demont, G. Molnár and A. Bousseksou, physica status solidi (a), 2006, 203, n/a-n/a.

22. A. Bousseksou, G. Molnar and G. Matouzenko, European Journal of Inorganic Chemistry, 2004, DOI: 10.1002/ejic.200400571, 4353-4369.

23. S. Bonhommeau, T. Guillon, L. M. Lawson Daku, P. Demont, J. Sanchez Costa, J. F. Letard, G. Molnar and A. Bousseksou, Angew Chem Int Ed Engl, 2006, 45, 1625-1629.

24. C. Lefter, I. y. A. Gural'skiy, H. Peng, G. Molnár, L. Salmon, A. Rotaru, A. Bousseksou and P. Demont, physica status solidi (RRL) - Rapid Research Letters, 2014, 8, 191-193.

25. A. Rotaru, I. A. Gural'skiy, G. Molnar, L. Salmon, P. Demont and A. Bousseksou, Chem Commun (Camb), 2012, 48, 4163-4165.

26. C. Lefter, R. Tan, J. Dugay, S. Tricard, G. Molnar, L. Salmon, J. Carrey, A. Rotaru and A. Bousseksou, Physical Chemistry Chemical Physics, 2015, 17, 5151-5154.

27. C. Lefter, S. Tricard, H. Peng, G. Molnár, L. Salmon, P. Demont, A. Rotaru and A. Bousseksou, The Journal of Physical Chemistry C, 2015, 119, 85228529.

28. J. Dugay, M. Giménez-Marqués, T. Kozlova, H. W. Zandbergen, E. Coronado and H. S. J. van der Zant, Advanced Materials, 2015, 27, 1288-1293.

29. T. G. Gopakumar, F. Matino, H. Naggert, A. Bannwarth, F. Tuczek and R. Berndt, Angewandte Chemie International Edition, 2012, 51, 6262-6266.

30. M. Gruber, V. Davesne, M. Bowen, S. Boukari, E. Beaurepaire, W. Wulfhekel and T. Miyamachi, Physical Review B, 2014, 89, 195415.

31. M. Matsuda and H. Tajima, Chemistry Letters, 2007, 36, 700-701.

32. T. Mahfoud, G. b. Molnár, S. Cobo, L. Salmon, C. Thibault, C. Vieu, P. Demont and A. Bousseksou, Applied Physics Letters, 2011, 99, 053307.

33. M. Cavallini, Phys Chem Chem Phys, 2012, 14, 11867-11876.

34. C. M. Quintero, I. y. A. Gural'skiy, L. Salmon, G. Molnár, C. Bergaud and A. Bousseksou, Journal of Materials Chemistry, 2012, 22, 3745.

35. M. Rubio, R. Hernández, A. Nogales, A. Roig and D. López, European Polymer Journal, 2011, 47, 52-60.

36. S. Cobo, G. Molnár, J. A. Real and A. Bousseksou, Angewandte Chemie International Edition, 2006, 45, 5786-5789.

37. Y. Chen, J. G. Ma, J. J. Zhang, W. Shi, P. Cheng, D. Z. Liao and S. P. Yan, Chem Commun (Camb), 2010, 46, 5073-5075.

38. S. W. Lee, J. W. Lee, S. H. Jeong, I. W. Park, Y. M. Kim and J. I. Jin, Synthetic Metals, 2004, 142, 243-249.

39. S. Shi, G. Schmerber, J. Arabski, J. B. Beaufrand, D. J. Kim, S. Boukari, M. Bowen, N. T. Kemp, N. Viart, G. Rogez, E. Beaurepaire, H. Aubriet, J. Petersen, C. Becker and D. Ruch, Applied Physics Letters, 2009, 95, 043303 043303.

40. H. Naggert, A. Bannwarth, S. Chemnitz, T. von Hofe, E. Quandt and F. Tuczek, Dalton Trans, 2011, 40, 6364-6366.

41. T. Palamarciuc, J. C. Oberg, F. El Hallak, C. F. Hirjibehedin, M. Serri, S. Heutz, J.-F. Létard and P. Rosa, Journal of Materials Chemistry, 2012, 22, 9690.

42. V. Davesne, M. Gruber, M. Studniarek, W. H. Doh, S. Zafeiratos, L. Joly, F. Sirotti, M. G. Silly, A. B. Gaspar, J. A. Real, G. Schmerber, M. Bowen, W. Weber, S. Boukari, V. Da Costa, J. Arabski, W. Wulfhekel and E. Beaurepaire, The Journal of Chemical Physics, 2015, 142, 194702. 
43. D. Tanaka, N. Aketa, H. Tanaka, T. Tamaki, T. Inose, T. Akai, H. Toyama, O. Sakata, H. Tajiri and T. Ogawa, Chemical Communications, 2014, 50, 1007410077.

44. I. Bräunlich, A. Sánchez-Ferrer, M. Bauer, R. Schepper, P. Knüsel, J. Dshemuchadse, R. Mezzenga and W. Caseri, Inorg Chem, 2014, 53, 35463557.

45. I. Bräunlich, S. Lienemann, C. Mair, P. Smith and W. Caseri, Journal of Materials Science, 2015, DOI: 10.1007/s10853-014-8704-3, 1-10.

46. M. C. H. McKubre and D. D. Macdonald, in Impedance Spectroscopy, John Wiley \& Sons, Inc., 2005, DOI: 10.1002/0471716243.ch3, pp. 129-204.

47. P. J. van Koningsbruggen, Y. Garcia, E. Codjovi, R. Lapouyade, O. Kahn, L. Fournès and L. Rabardel, Journal of Materials Chemistry, 1997, 7, 2069-2075.

48. M. M. Dîrtu, A. D. Naik, J. Marchand-Brynaert and Y. Garcia, Journal of Physics: Conference Series, 2010, 217, 012085.

49. A. Sanchez-Ferrer, I. Braunlich, J. Ruokolainen, M. Bauer, R. Schepper, P. Smith, W. Caseri and R. Mezzenga, RSC Advances, 2014, 4, 60842-60852.

50. A. B. Gaspar and M. Seredyuk, Coordination Chemistry Reviews, 2014, 268, 41-58.

51. K. Kuroiwa, T. Shibata, S. Sasaki, M. Ohba, A. Takahara, T. Kunitake and N. Kimizuka, Journal of Polymer Science Part A: Polymer Chemistry, 2006, 44, 5192-5202.

52. M. Rubio and D. López, European Polymer Journal, 2009, 45, 3339-3346.

53. O. Roubeau, A. Colin, V. Schmitt and R. Clérac, Angewandte Chemie International Edition, 2004, 43, 3283-3286.

54. O. Roubeau, J. M. Alcazar Gomez, E. Balskus, J. J. A. Kolnaar, J. G. Haasnoot and J. Reedijk, New Journal of Chemistry, 2001, 25, 144-150.

55. O. Roubeau, J. G. Haasnoot, E. Codjovi, F. Varret and J. Reedijk, Chemistry of Materials, 2002, 14, 2559-2566.

56. A. Eckelt, J. Eckelt and B. Wolf, in Encyclopedia of Polymer Science and Technology, John Wiley \& Sons, Inc., 2002, DOI: 10.1002/0471440264.pst345.

57. D. J. Blundell, A. Keller and A. J. Kovacs, Journal of Polymer Science Part B: Polymer Letters, 1966, 4, 481-486.

58. M. Li, I. Katsouras, C. Piliego, G. Glasser, I. Lieberwirth, P. W. M. Blom and D. M. de Leeuw, Journal of Materials Chemistry C, 2013, 1, 7695-7702.

59. P. Gütlich, A. B. Gaspar and Y. Garcia, Beilstein Journal of Organic Chemistry, 2013, 9, 342-391.

60. H. J. Shepherd, C. M. Quintero, G. Molnár, L. Salmon and A. Bousseksou, in Spin-Crossover Materials, John Wiley \& Sons Ltd, 2013, DOI: 10.1002/9781118519301.ch13, pp. 347-373.

61. A. Hauser, 2004, 233, 49-58.

62. I. A. Gural'skiy, C. M. Quintero, K. Abdul-Kader, M. Lopes, C. BartualMurgui, L. Salmon, P. X. Zhao, G. Molnar, D. Astruc and A. Bousseksou, Journal of Nanophotonics, 2012, 6.

63. P. Gütlich, A. Hauser and H. Spiering, Angewandte Chemie International Edition in English, 1994, 33, 2024-2054.

64. M. M. Dîrtu, C. Neuhausen, A. D. Naik, A. Rotaru, L. Spinu and Y. Garcia, Inorg Chem, 2010, 49, 5723-5736.

65. A. Urakawa, W. Van Beek, M. a. Monrabal-Capilla, J. R. n. Galán-Mascarós, L. Palin and M. Milanesio, The Journal of Physical Chemistry C, 2010, 115, 1323-1329.

66. S. Cobo, G. Molnar, J. A. Real and A. Bousseksou, Angew Chem Int Ed Engl, 2006, 45, 5786-5789. 

(a)

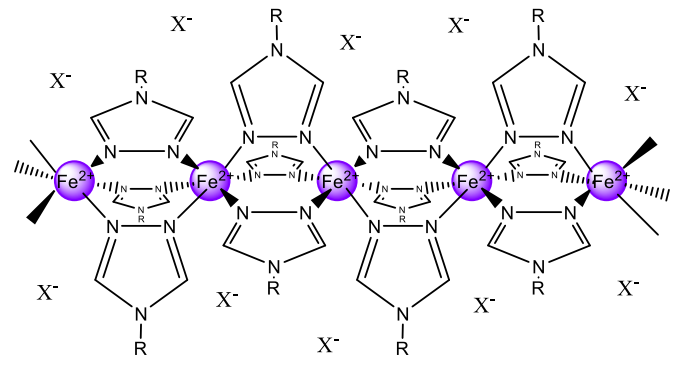

(b)

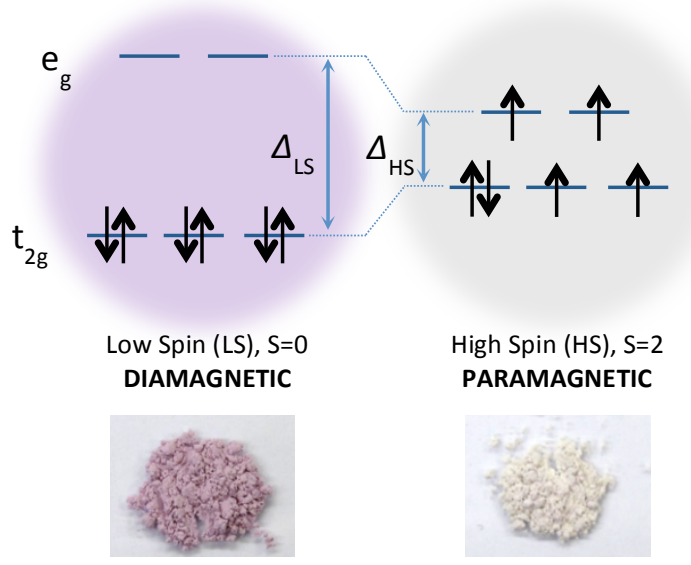

(c)

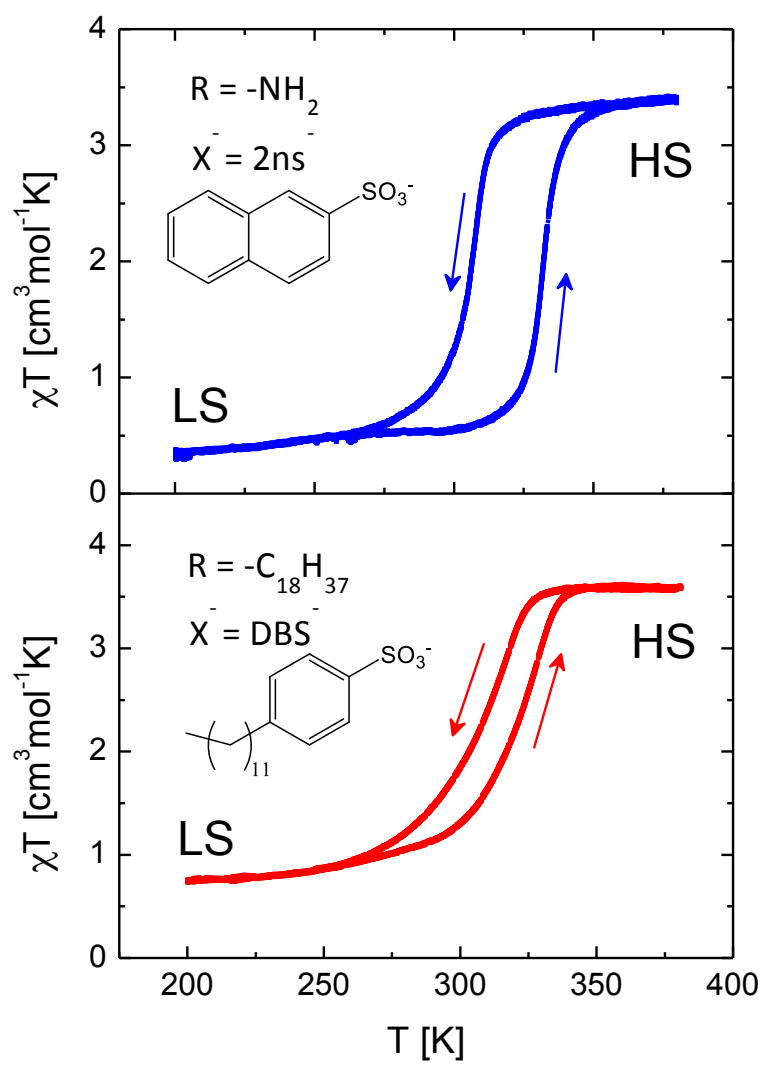

Figure 1. (a) Chemical structure of Fe(II)-triazole polymers. (b) Simplified electronic configurations of $3 d$ orbitals in Fe(II) centres: large ligand fields $\left(\Delta_{\mathrm{LS}}\right)$ lead to a diamagnetic low spin arrangement $(L S, S=0)$ while weaker fields $\left(\Delta_{H S}\right)$ favour a paramagnetic high spin state (HS, S=2). SCO is the reversible LS-HS interconversion which occurs upon external perturbation. Fe(II)-triazole polymers also display SCO-related thermochromism (pictures of powders in LS and HS state) (c) Temperature dependence of $\chi^{\top}$ for powders of compounds 1 and 2 at $1 \mathrm{~K} / \mathrm{min}$ heating/cooling rate, showing SCO with hysteresis around room temperature. Inset: chemical structure of specific counter anions and R-groups on the triazole ligands. 


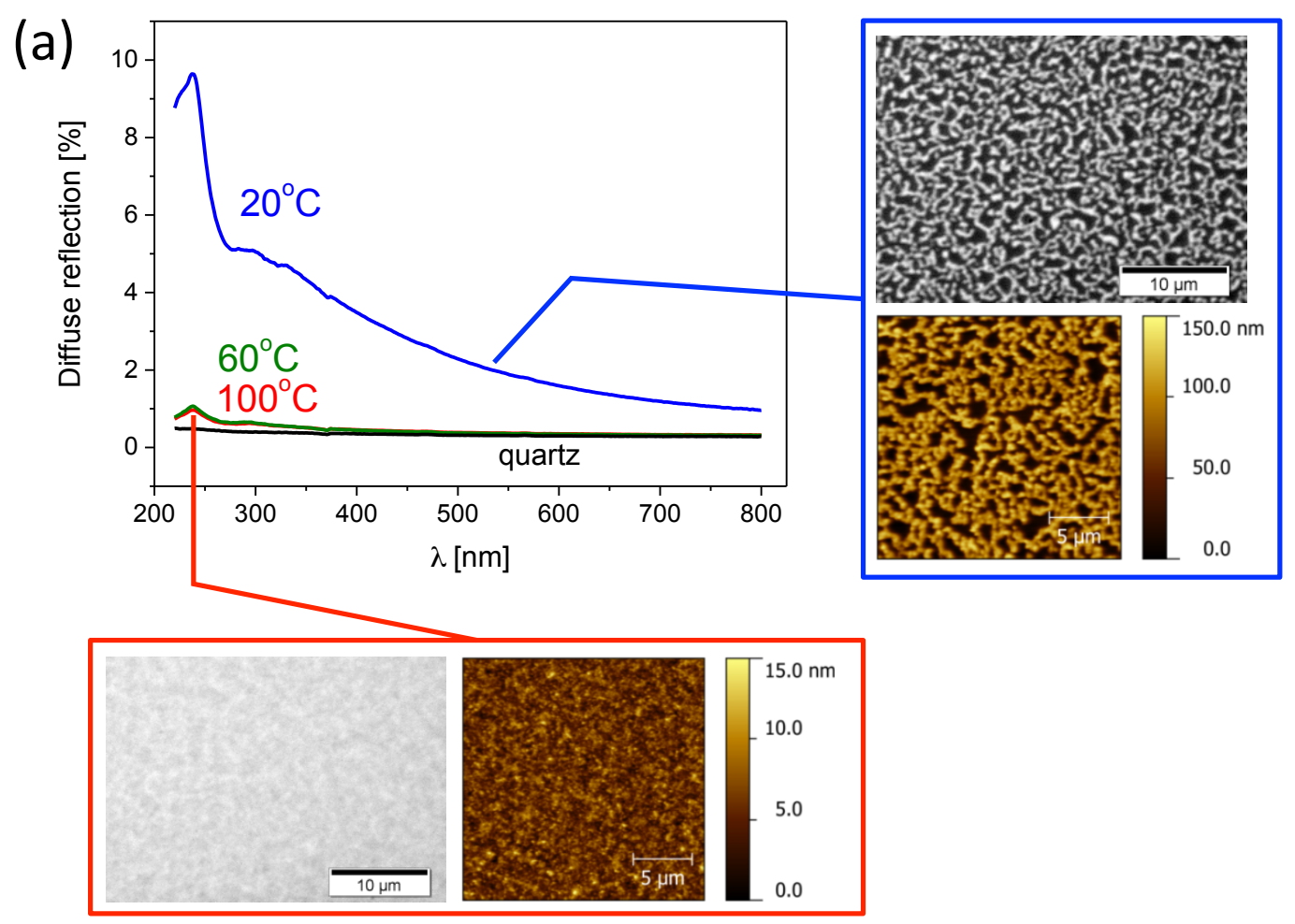

(b)

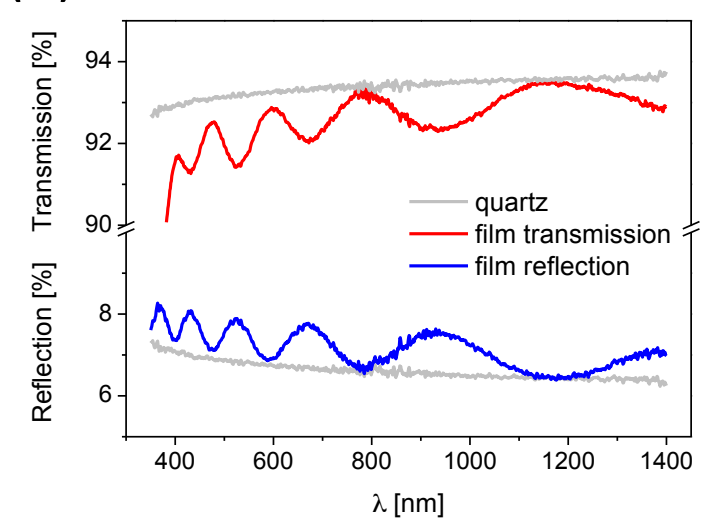

(c)

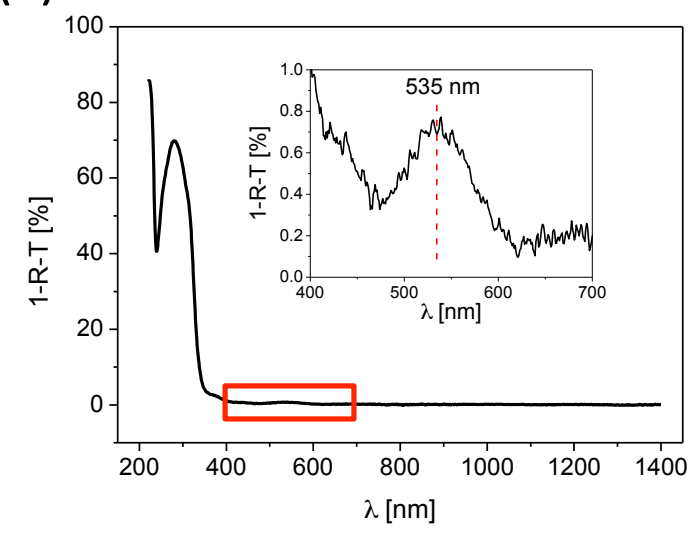

Figure 2. (a) Diffuse reflection spectra in the UV and visible range for quartz substrates and films cast from solutions of 1 at $20{ }^{\circ} \mathrm{C}$ (non-homogeneous deposit), $60{ }^{\circ} \mathrm{C}$ and $100{ }^{\circ} \mathrm{C}$ (uniform $30 \mathrm{~nm}$ thickness) with corresponding optical microscopy (50x, reflection mode) and AFM topography images. (b) Transmission and reflection spectra in the UV-Vis-NIR from a $780 \mathrm{~nm}$ thickness film of 2 showing Fabry-Perot oscillations. (c) Absorption of the $750 \mathrm{~nm}$ film of 2 calculated as A=1-R-T. Inset: identification of the $535 \mathrm{~nm}$ band characteristic of the LS state and associated with the polymer thermochromism. 

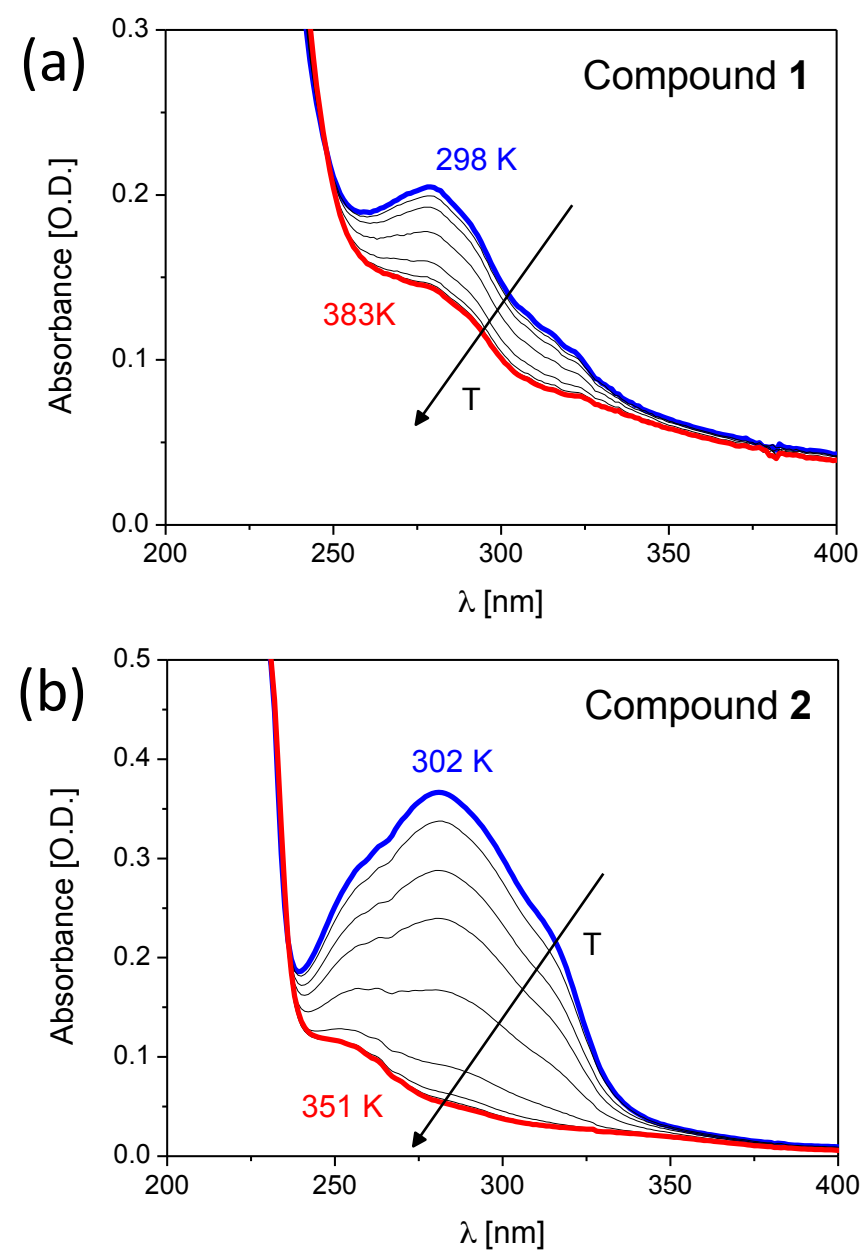

Figure 3. Temperature dependent UV absorbance measured in air for a $40 \mathrm{~nm}$ film of 1 (a) and a $480 \mathrm{~nm}$ film of $\mathbf{2}$ (b), displaying the LS to HS transition on heating and confirming the SCO switching retention in thin layers. 
(a)
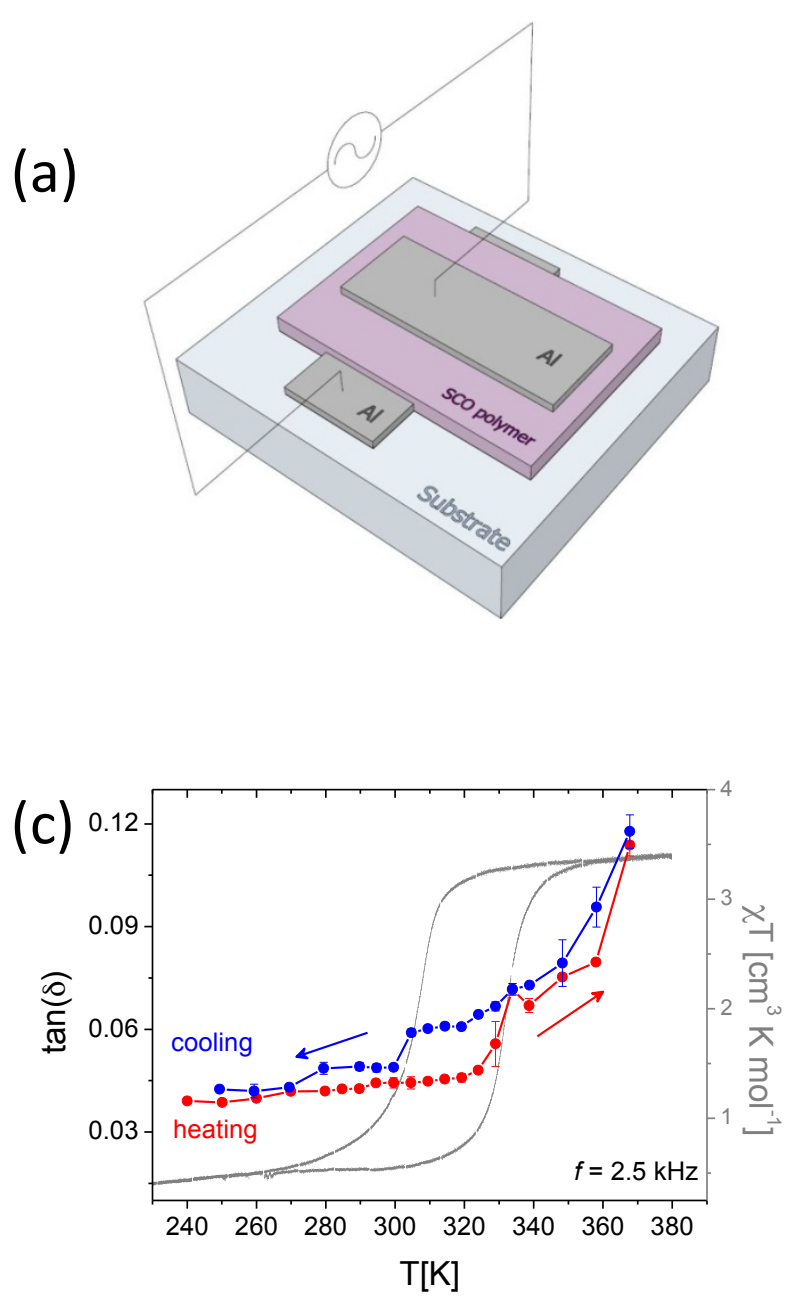
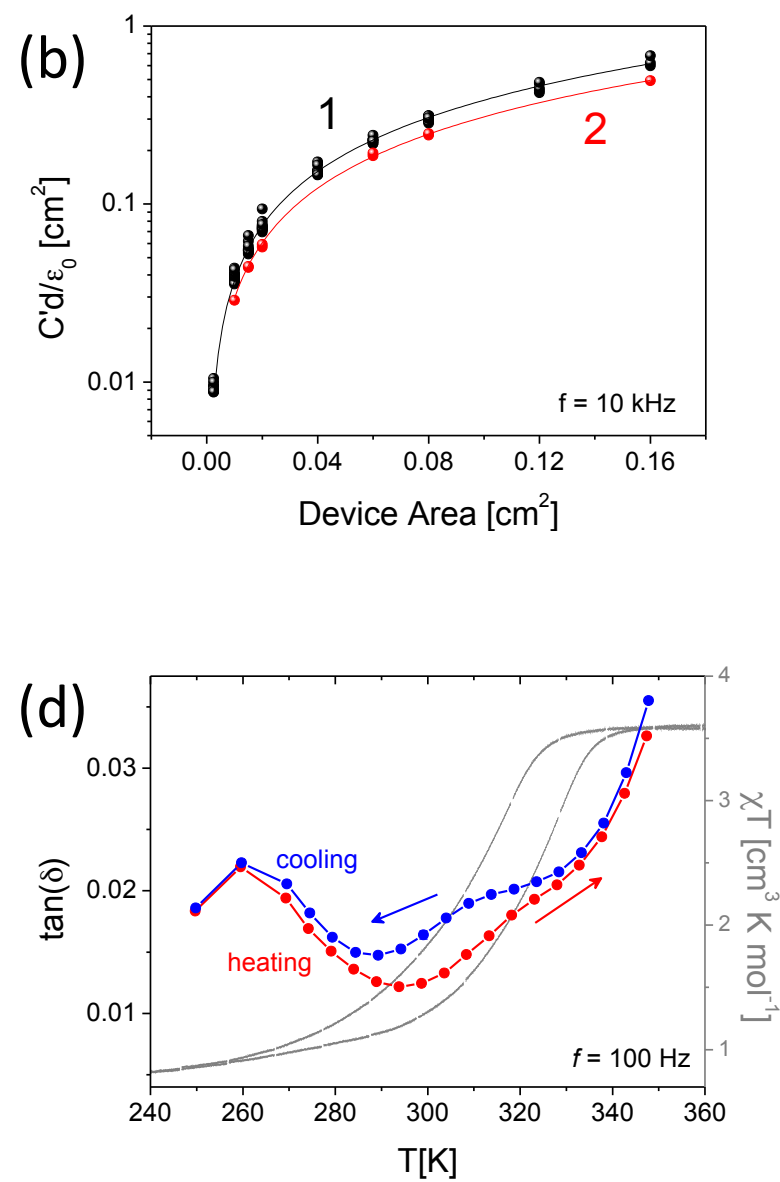

Figure 4. (a) 3D sketch of the M-I-M configuration adopted for the impedance spectroscopy measurements. (b) Dependence of $C^{\prime} d / \varepsilon_{0}$ with device area for MIM devices embedding thin films of $\mathbf{1}$ (black) and $\mathbf{2}$ (red). Interpolation of data is shown by the line of corresponding colour. (c) Thermal hysteresis of $\tan (\delta)$ at $2.5 \mathrm{kHz}$ for a $30 \mathrm{~nm}$ thickness film of 1 . (d) Thermal hysteresis of $\tan (\delta)$ at $100 \mathrm{~Hz}$ for a $400 \mathrm{~nm}$ thickness film of 2. Both (c) and (d) also display the hysteresis of the magnetic susceptibility from powders in grey. The error bars indicate the standard deviations of the measured values. 


\section{Supplementary Information}

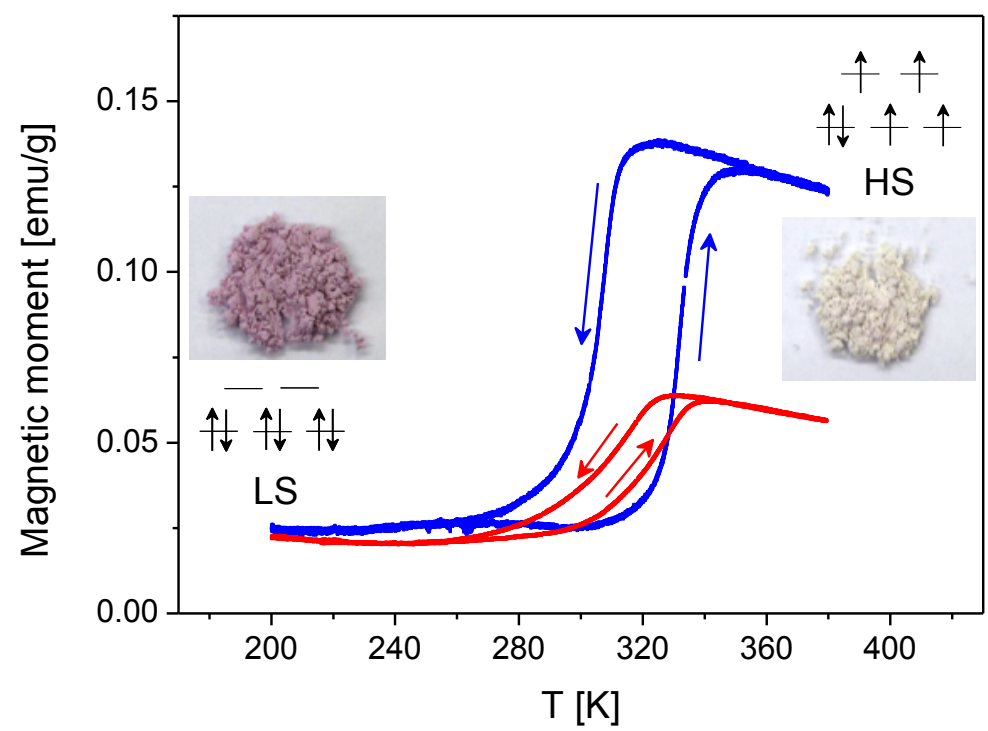

Figure S1. Temperature dependence of the magnetic moment normalized by weight for powders of compounds 1 and 2 at $1 \mathrm{~K} / \mathrm{min}$ heating/cooling rate. The different intensity of the HS paramagnetic signal is due to the higher Fe(II) density in $\mathbf{1}$ (molar mass $=722.5$ $\mathrm{g} / \mathrm{mol}$ ) vs 2 (molar mass $=1671.5 \mathrm{~g} / \mathrm{mol}$ ). 


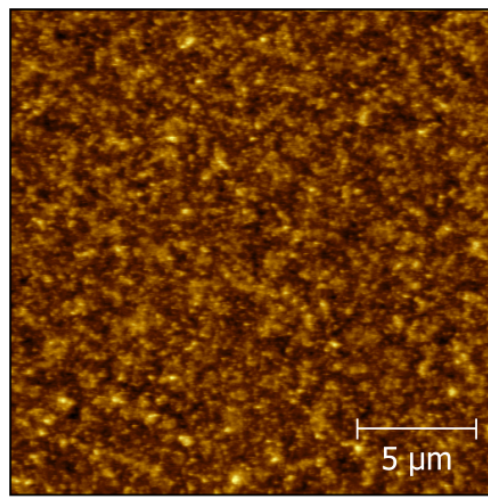

$15.0 \mathrm{~nm}$
12.0
10.0
8.0
6.0
4.0
2.0
0.0

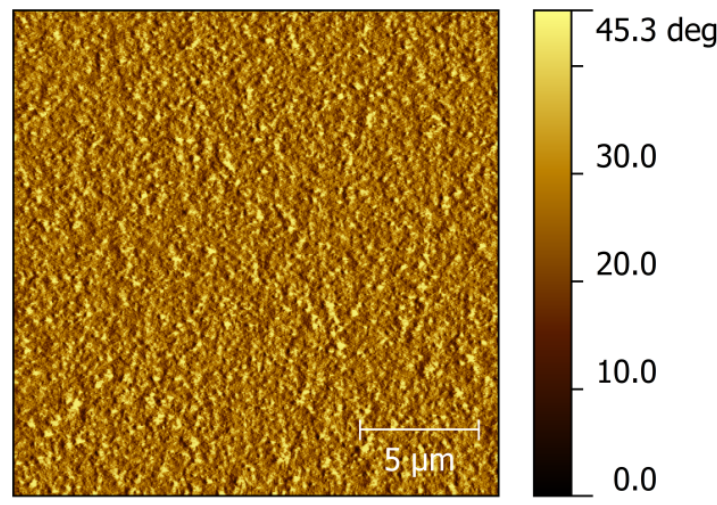

(a)
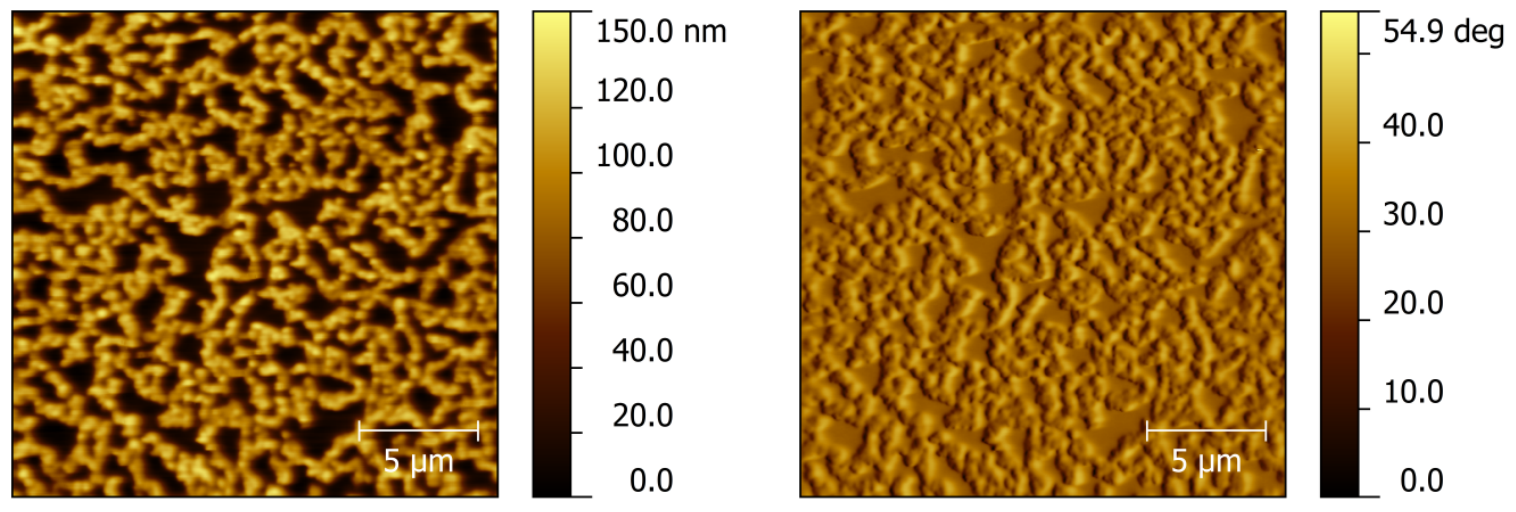

(b)

Figure S2. AFM topography (left) and phase (right) images of the films of compound $\mathbf{1}$ cast from solutions at $100{ }^{\circ} \mathrm{C}(\mathrm{a})$ and at $20^{\circ} \mathrm{C}$ (b) (see Figure 2a).

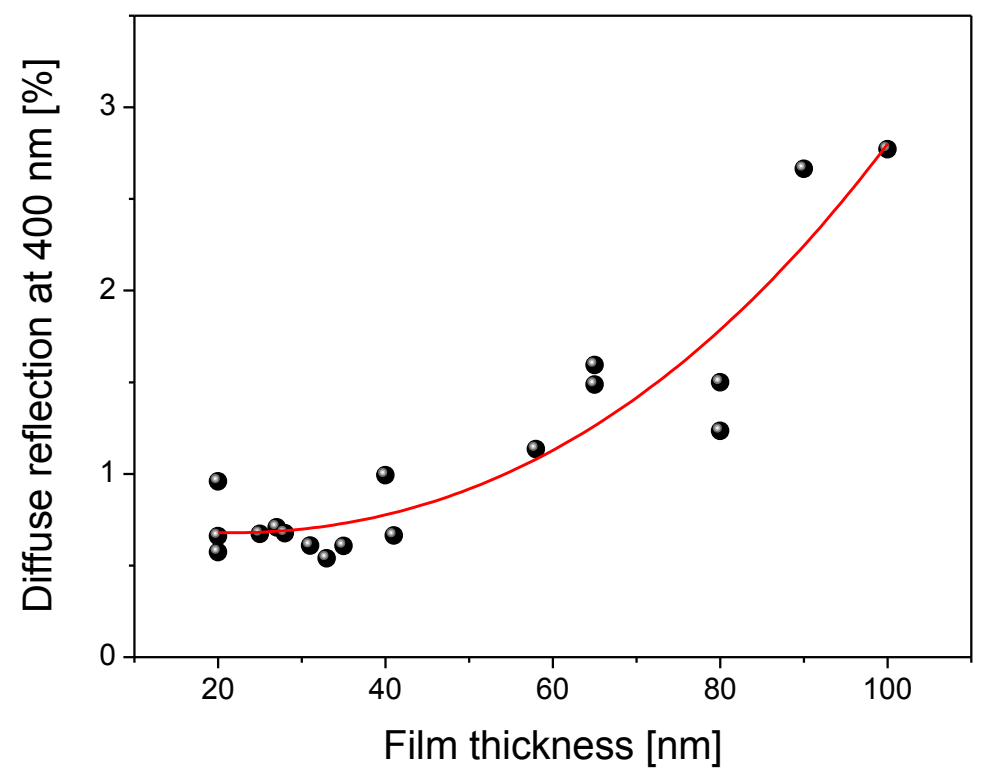

Figure S3. Diffuse reflection values at $400 \mathrm{~nm}$ as a function of film thickness from hot cast films of compound $\mathbf{1}$. The red line is intended as a guide to the eye and emphasises the increasing degree of light scattering with increasing film thickness. 


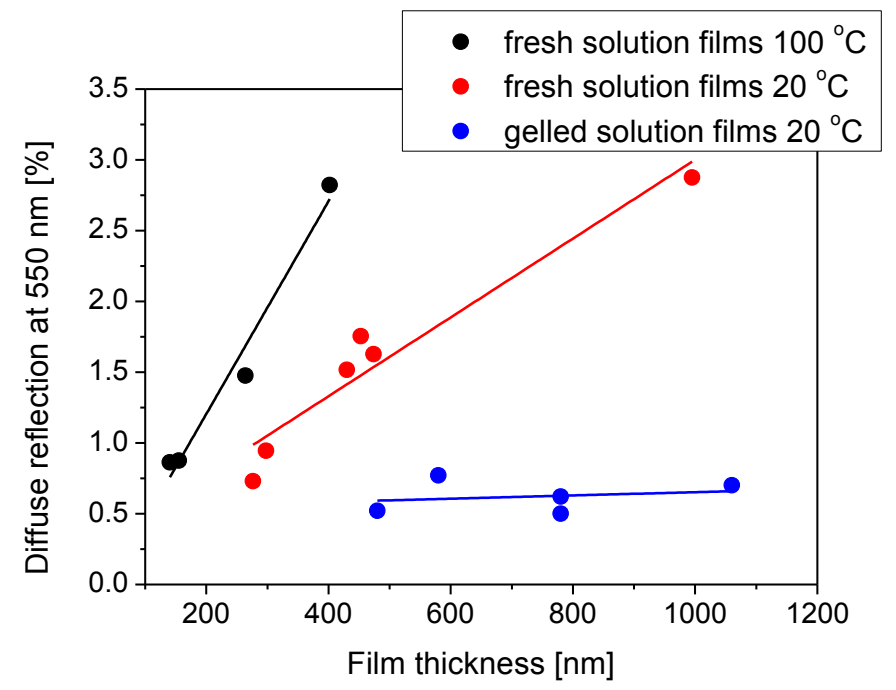

(a)

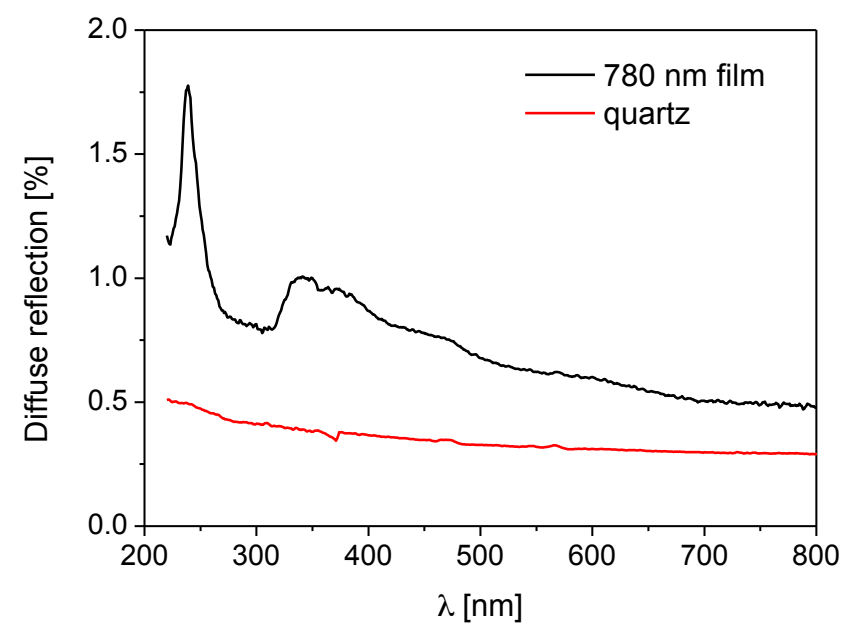

(b)
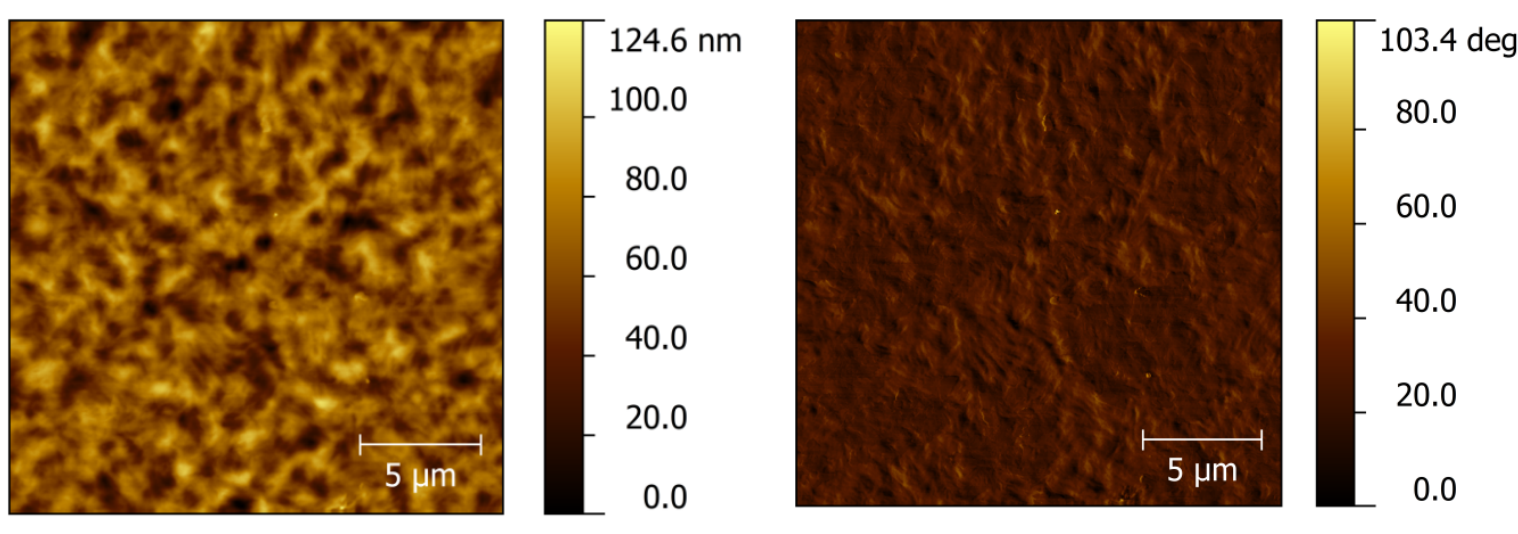

(c)

Figure S4. (a) Diffuse reflection values at $550 \mathrm{~nm}$ as a function of the thickness for films of compound 2 cast from fresh (at $100{ }^{\circ} \mathrm{C}$ and $20{ }^{\circ} \mathrm{C}$ ) and gelled solutions. Scattering is found to be very low in films spin-coated from gels. (Lines are shown to guide the eye) (b) Diffuse reflection spectra recorded for a fused silica substrate (red line) and $780 \mathrm{~nm}$ thickness film of 2 (black line). (c) AFM topography (left) and phase (right) images of a $780 \mathrm{~nm}$ thickness film. Rms roughness is $15.8 \mathrm{~nm}$. 


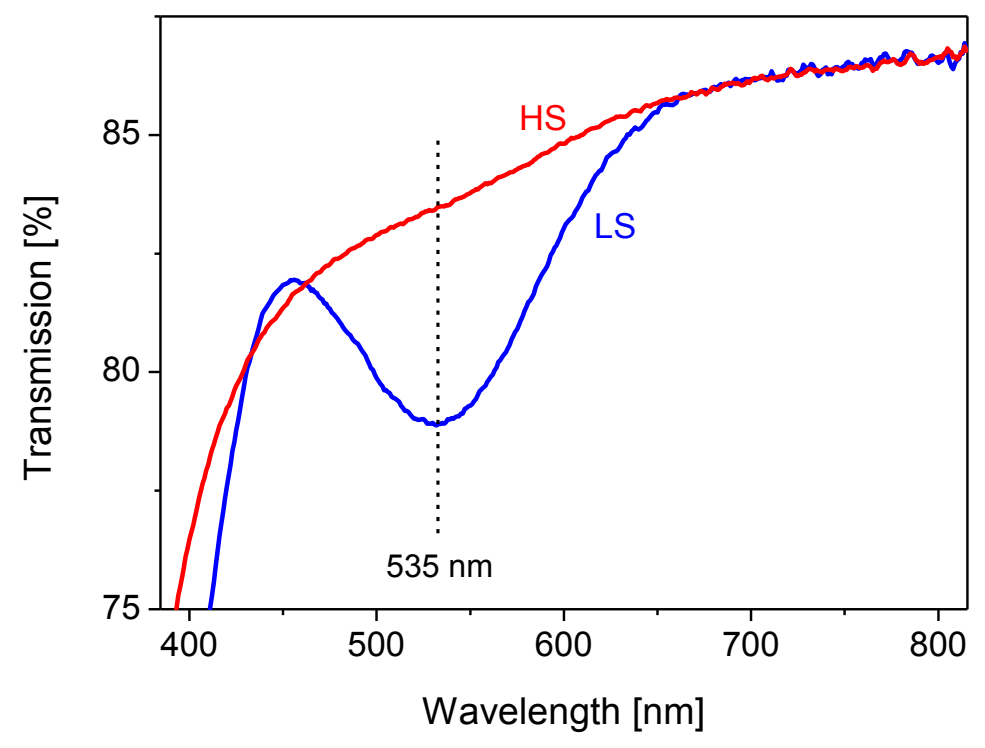

Figure S5. Transmission UV-Vis spectra for a $\sim 3 \mu \mathrm{m}$ thickness dropcast film of $\mathbf{1}$ in the LS (blue, RT) and $\mathrm{HS}\left(\mathrm{red},>90^{\circ} \mathrm{C}\right.$ ) states, showing retention of the thermochromism associated with SCO. 

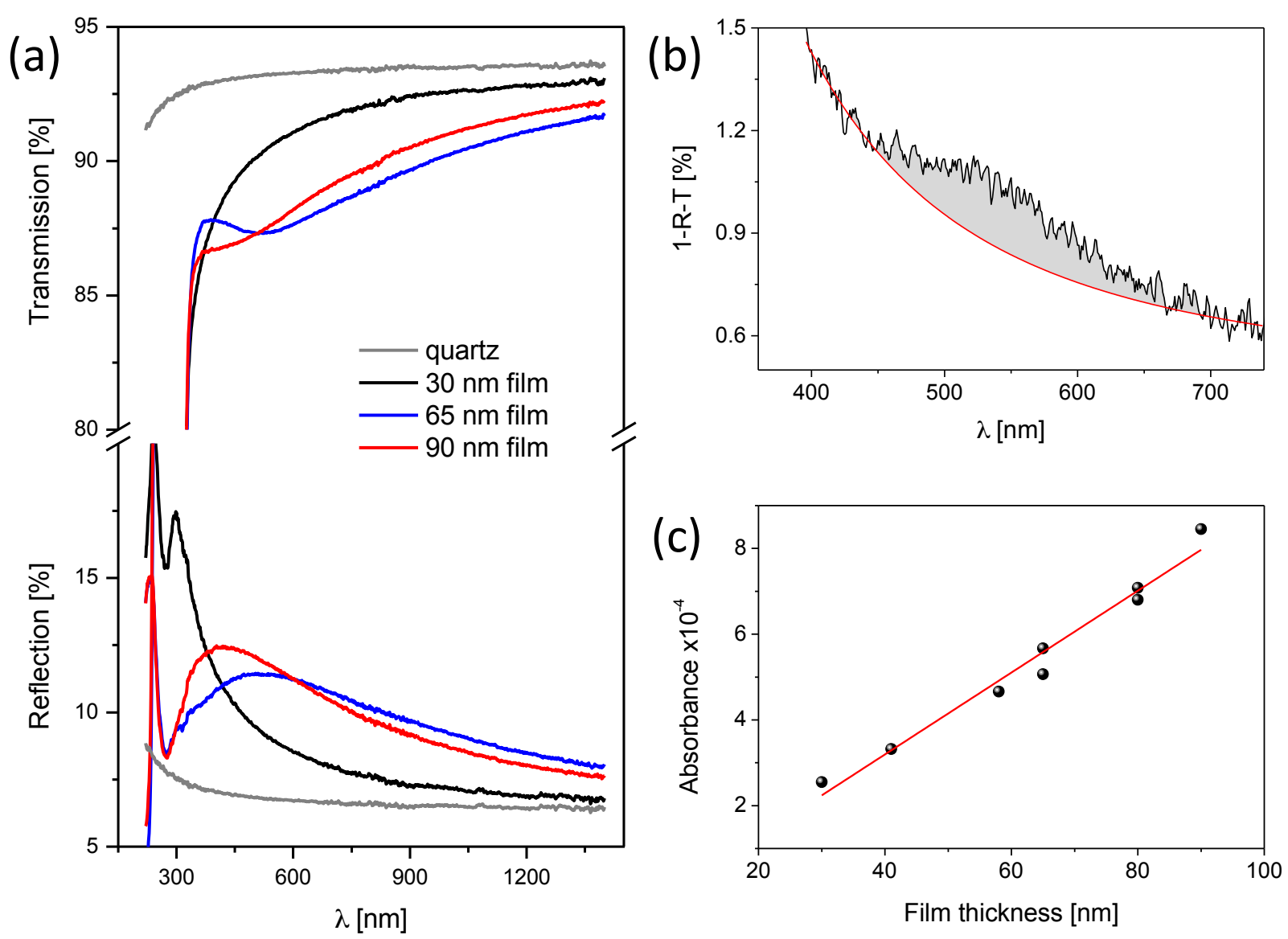

Figure S6. (a) Transmission and reflection spectra in the UV-Vis range for a fused silica substrate (grey line) and 30 (black line), 65 (red line) and 90 (blue line) nm thickness films of compound 1 recorded at room temperature. Fabry-Perot interference fringes feature in both the $T$ and R spectra. (b) Absorption from a $90 \mathrm{~nm}$ thickness film calculated as 1-R-T, showing the absorption centred at $535 \mathrm{~nm}$ characteristic of the LS state. The red line used as a baseline is obtained via non-linear fitting (Abs $\left.=a+b / \lambda^{2}+c / \lambda^{4}\right)$. (c) Dependence of the absorbance at $535 \mathrm{~nm}$ on the film thickness and linear interpolation of the data (red line).

The absorbance (Abs) was calculated as

$$
A b s=\log [100 /(R+T)]
$$

where $\mathrm{R}$ and $\mathrm{T}$ are expressed as $\%$ values. Knowing the thickness, we can estimate the absorption coefficient $(\alpha)$ as directly proportional to the absorbance according to the BeerLambert expression; a linear fit of the absorbance at 535 as a function of thickness yields $\alpha$. 


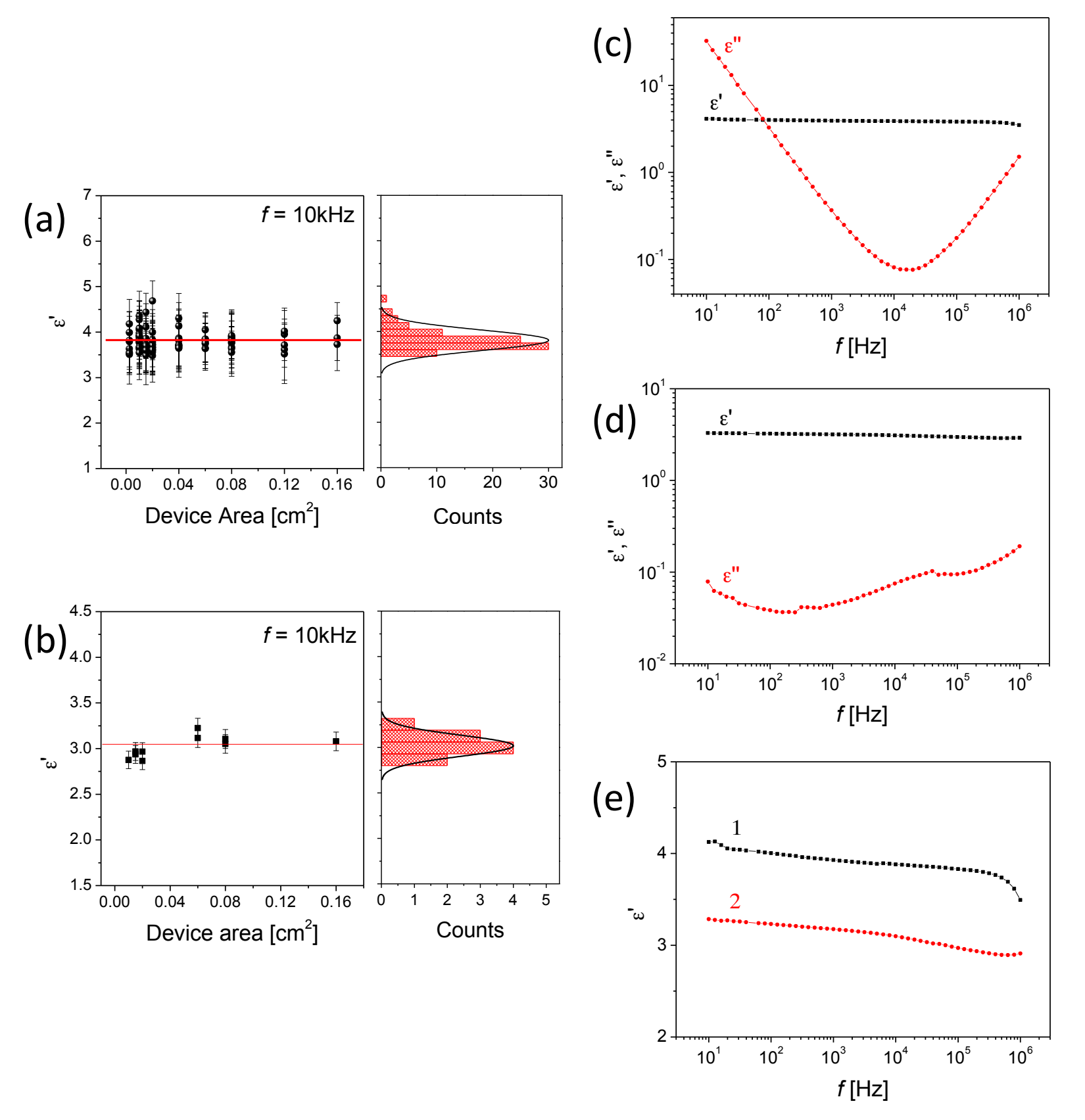

Figure S7. $\varepsilon^{\prime}$ statistics from devices of different areas and film thickness for compound 1 (a) and 2 (b). Typical frequency response for $\varepsilon^{\prime}$ and $\varepsilon^{\prime \prime}$ for compound $\mathbf{1}$ (c) (device area: 0.02 $\mathrm{cm}^{2}$, film thickness: $30 \mathrm{~nm}$ ), compound 2 (d) (device area: $0.06 \mathrm{~cm}^{2}$, film thickness: $395 \mathrm{~nm}$ ) and comparison of $\varepsilon^{\prime}$ values for the two materials (e). 

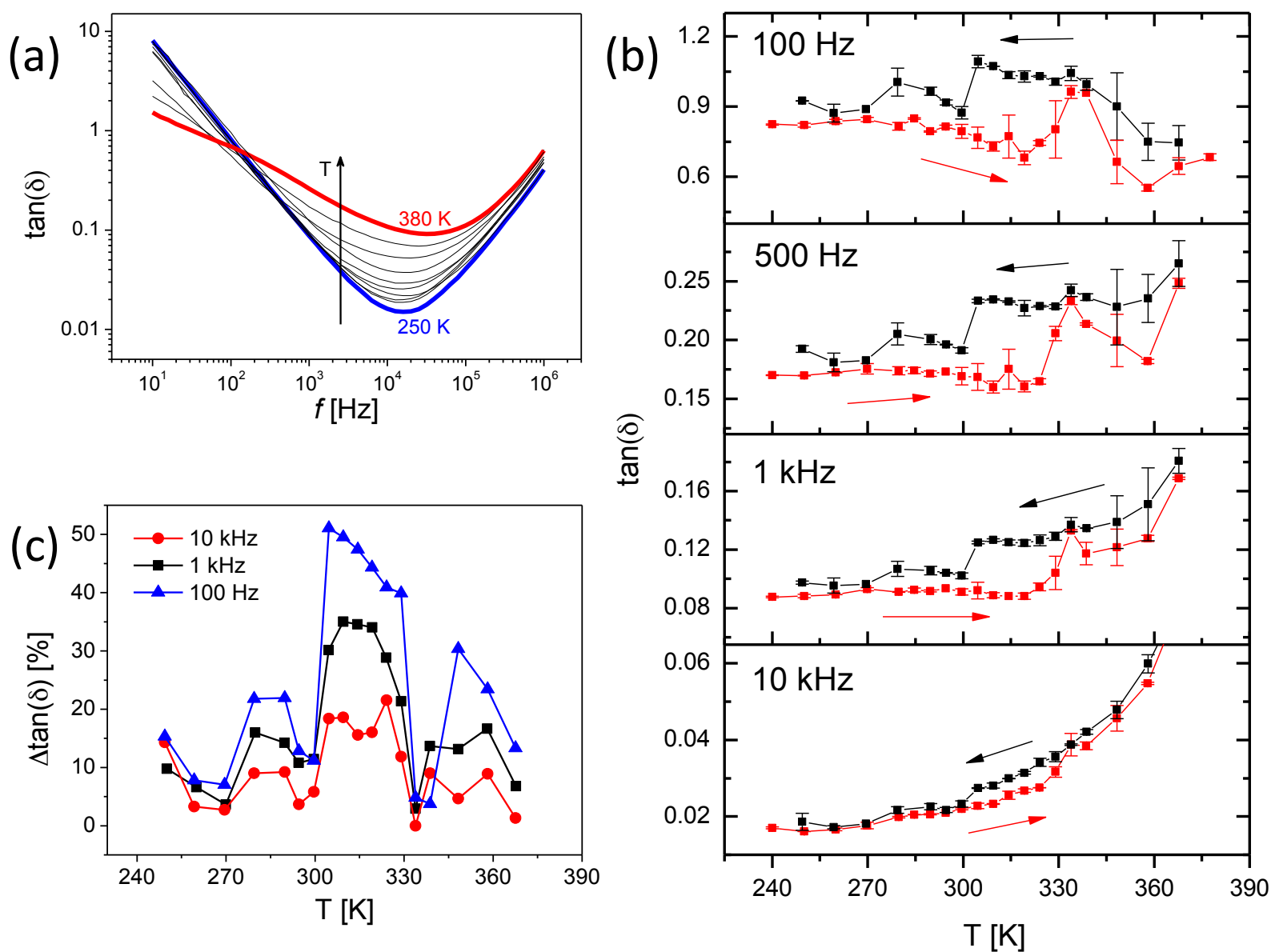

Figure S8. (a) Frequency dependence of $\tan (\delta)$ at different temperatures on heating a $30 \mathrm{~nm}$ film of 1. (b) Thermal hysteresis of $\tan (\delta)$ at different frequency values for the same film. (c) Difference between the $\tan (\delta)$ values measured on cooling and on heating, as a function of temperature at $f=100 \mathrm{~Hz}$ (red), $f=1 \mathrm{kHz}$ (black) and $f=10 \mathrm{kHz}$ (blue). 

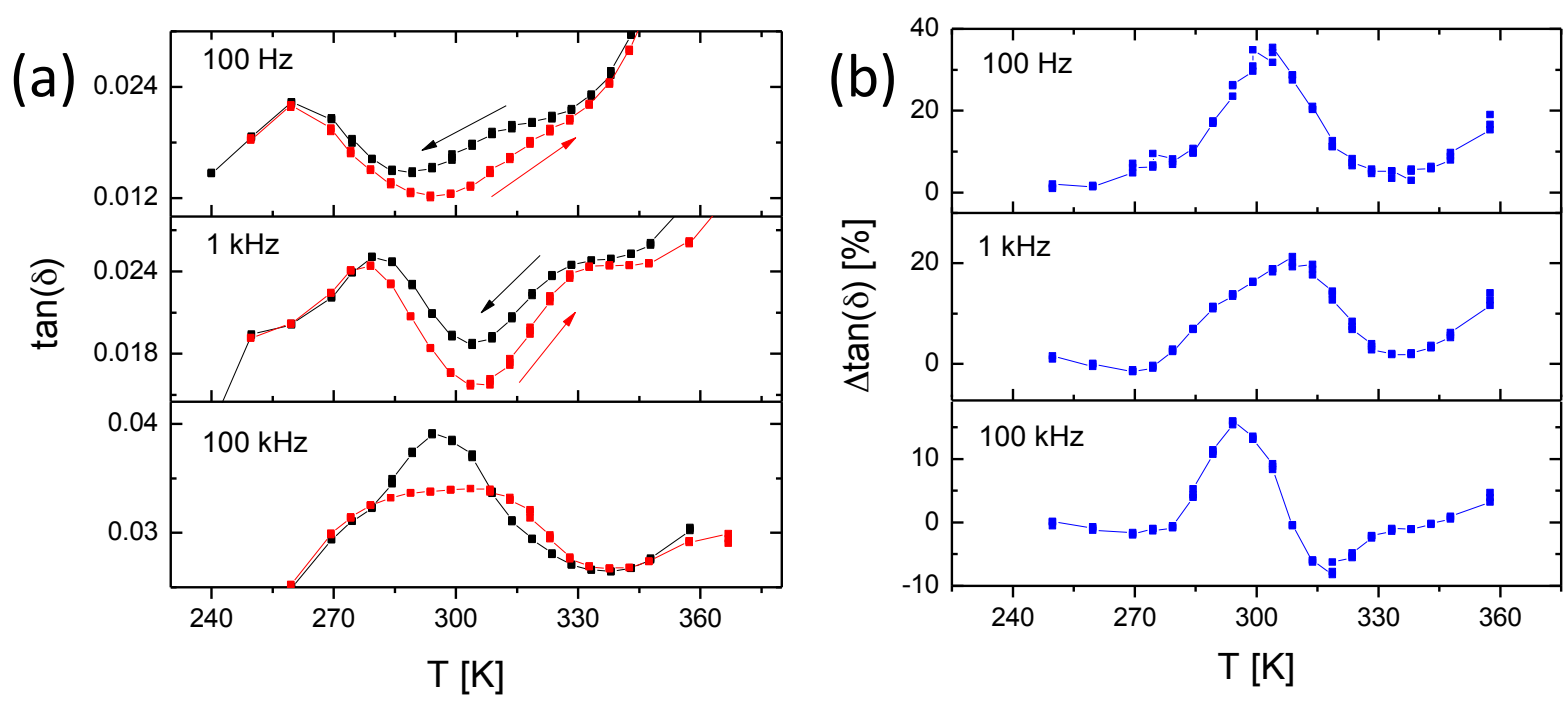

Figure 59. (a) Thermal hysteresis of $\tan (\delta)$ at different frequency values for $395 \mathrm{~nm}$ thickness film of 2. (b) Difference between the $\tan (\delta)$ values measured on cooling and on heating at different frequency values. 